\title{
A atualidade da teoria dos circuitos na compreensão das práticas econômicas populares: o caso da Economia Criativa em Araraquara/SP
}

\section{The relevance of circuit theory in understanding popular economic practices: the case of Creative Economy in Araraquara/SP}

\author{
Renan Augusto Ramos $\bowtie$ (iD \\ Faculdade de Ciências e Letras de Araraquara, Universidade Estadual Paulista \\ Júlio de Mesquita Filho, Araraquara, São Paulo, Brasil \\ E-mail para correspondência: renan.aug.95@gmail.com
}

Recebido (Received): 09/03/2020

Aceito (Accepted):13/04/2020

\begin{abstract}
Resumo: As práticas econômicas alternativas estão em evidência no contexto brasileiro do século XXI. Constatamos, nesse sentido, a existência de feiras econômicas em Araraquara que reforçam a temática da economia urbana. Dessa maneira, sob o apoio de um governo municipal eleito em 2016 com o slogan "Cidade Solidária e Participativa", é necessário que se construam iniciativas de compreensão do fenômeno da Economia Solidária e Criativa no município de Araraquara. Para tanto, recorremos à Geografia para fornecer arcabouço teórico-metodológico de referência ao entendimento da problemática. Em específico, foi utilizada a teoria dos circuitos econômicos de Milton Santos (2018), que constata, nos países subdesenvolvidos, a fragmentação da economia urbana em dois circuitos. A proposta, então, qualificou essas práticas econômicas como representativas do circuito inferior da economia urbana, que almeja fornecer ocupação nos circuitos gerais da produção de valores. A partir disso, com a realização de uma pesquisa empírica nas edições da "Rolêfeira", aplicação de entrevistas e questionários com os sujeitos sociais de interesse, a finalidade do trabalho foi observar a importância desses empreendimentos enquanto estratégias que buscam superar o desemprego e promover o desenvolvimento econômico e social em Araraquara, bem como compreender a própria interface de comunicação estabelecida entre a sociedade civil e o governo municipal.
\end{abstract}

Palavras-chave: Economia urbana; Economia solidária; Economia criativa; Desenvolvimento social.

Abstract: Alternative economic practices are in evidence in the 21 st century brazilian's context. In this sense, we note the existence of economic fairs in Araraquara that reinforce the theme of the urban economy. Thus, under the support of a municipal government elected in 2016 with the slogan "Solidary and Participative City", it is necessary to build initiatives of understanding the phenomenon of Solidarity and Creative Economy in the municipality of Araraquara. For this, we use Geography to provide a theoreticalmethodological framework for the understanding of the problem. In particular, the theory of economic circuits by Milton Santos (2018) is used, which founds in underdeveloped countries, a fragmentation of the urban economy into two circuits. The proposal, then, qualified these economic practices as representative of the lower circuit of the urban economy, which provides occupation in the general circuits of value production. From this, with an empirical research carried out in the editions of "Rolefeira", applications of interviews and questionnaires with social subjects of interest, this article aimed to observe the importance of these ventures as strategies to overcome unemployment and promoting economic and social development in Araraquara, as well as understanding the communication interface between civil society and the municipal government.

Keywords: Urban economy; Solidary economy; Creative economy; Social development. 


\section{Introdução}

O contexto atual da acumulação flexível do capital reconheceu, dentre uma série de mudanças no mundo do trabalho, a incorporação cada vez mais seletiva dos indivíduos nos circuitos formais de geração de valores. Em certo sentido, é possível destacar essa problemática enquanto um fenômeno global, capaz de atingir os países desenvolvidos do capitalismo central e os próprios países denominados subdesenvolvidos. A insegurança presente no mundo do trabalho demarca os limites do atual sistema econômico que, baseado na "mão invisível", não foi capaz de assegurar benefícios aos trabalhadores em geral (GAIGER, 2015). Dessa forma, coloca-se em evidência a expansão de pequenas atividades econômicas como resposta adaptativa às situações de crise na contemporaneidade (HESPANHA, 2009).

O mundo do trabalho brasileiro é complexo, pois apresenta especificidades que se vinculam ao seu próprio processo histórico de formação (COSTA, 2016). Observam-se nas cidades as mais distintas estratégias econômicas que visam à inserção nos circuitos gerais de produção. A impossibilidade de rendas permanentes produzem iniciativas no espaço urbano que refletem o surgimento do chamado circuito inferior da economia (SANTOS, 2018). O alto grau de desigualdade socioeconômica sustenta uma divisão do trabalho marcada pela coexistência de iniciativas econômicas caracterizadas por distintos níveis de capitalização, organização e incorporação de tecnologias nos empreendimentos (SILVEIRA, 2015). Então, dessa maneira, cada vez mais se constatam práticas econômicas alternativas, inseridas no contexto maleável e múltiplo do mercado urbano de produção de valores. O diagnóstico atual coloca, no centro do debate, a crítica aos modelos de desenvolvimento pautados na lógica exclusiva das grandes empresas pelo seu caráter seletivo (GAIGER, 2015).

A partir disso, ampliam-se nos contextos socioespaciais os mais variados empreendimentos de geração da provisão dos sujeitos econômicos, marginalizados pelo processo capitalista em geral. A tendência do desenvolvimento capitalista assenta-se na subordinação das práticas não convencionais por meio da imposição da racionalidade dominante àquilo caracterizado como estranho ao seu funcionamento (HESPANHA, 2009). Entretanto, mesmo com esse movimento, é fundamental ressaltar o fortalecimento das iniciativas populares que vão à contramão desse projeto hegemônico da economia. $\mathrm{O}$ crescente número de práticas econômicas alternativas aponta para formas econômicas desenvolvidas em princípios não utilitaristas, percorridos por uma densa sociabilidade capaz de garantir a sobrevivência dos segmentos sociais mais diversos (GAIGER, 2009). Portanto, o enfoque deve ser colocado nesses projetos que combatem os contextos de pauperização e precarização da vida humana na atualidade (GAIGER, 2009).

O objetivo é trazer à tona a importância da compreensão sobre o mercado atual de produção de valores no Brasil. As dificuldades encontradas no mundo do trabalho remetem a um contexto de diversidade nas práticas econômicas existentes, alicerçadas na procura pela produção da provisão dos sujeitos. Dessa forma, o artigo propõe realizar um debate sobre as práticas econômicas alternativas no município de Araraquara. A partir de uma pesquisa empírica nas edições da "Rolêfeira", o trabalho reflete sobre a planificação da Economia Solidária e Criativa araraquarense em função das estratégias de superação do desemprego estrutural contemporâneo. A institucionalização desses espaços de troca se insere na agenda política enquanto iniciativas que, de certo modo, trabalham na direção da apropriação do espaço público (CARLOS, 2014). O enfoque se dá pela perspectiva analítica da valorização da praça como lugar de sociabilidade em potencial. Por fim, a revalorização do circuito inferior da economia urbana é colocada como uma alternativa viável para a gestão pública ao mesmo tempo em que promovem iniciativas culturais e artísticas de lazer a céu aberto.

\section{Apresentando o contexto da análise}

A cidade de Araraquara apresenta propensão ao estímulo de práticas alternativas da economia urbana. O município traz o slogan "Cidade Solidária e Participativa" como representativo de sua ação governamental. Dessa forma, o discurso de uma cidade que fomenta práticas econômicas não convencionais toma destaque. Esse mesmo processo de incentivos é coordenado por um desenho institucional da prefeitura que organiza as relações estabelecidas no interior dessas atividades econômicas. O município possui na Secretaria do Trabalho e de Desenvolvimento Econômico uma ramificação específica voltada para práticas econômicas alternativas. A Coordenadoria do Trabalho e de Economia Criativa e Solidária fornece o respaldo para que os espaços de troca sejam instituídos na prática social e, por conseguinte, é possível observar também a complexidade existente no interior da economia urbana. No entanto, para compreender o quadro apresentado, é necessário demarcar o contexto sociopolítico atual do município.

A discussão sobre Economia Solidária e Criativa no governo de Araraquara se intensifica, sobretudo no momento em que a prefeitura organiza, entre os dias 14 e 15 de julho de 2017, a $1^{\text {a }}$ Conferência de Economia 
Criativa e Solidária de Araraquara. O evento foi resultado de um esforço coletivo entre a gestão do município, especialistas no assunto, sociedade civil no geral e os responsáveis pelos empreendimentos econômicos em si. A temática transcorreu em razão do título "Desenvolvimento econômico local com trabalho decente: geração de renda e inclusão social". Nesse sentido, a proposta do cronograma era relacionar os conteúdos do enfrentamento ao desemprego e à pobreza, articulando com a possibilidade de estratégias de fomento, bem como de justiça social. A conferência funcionou como um instrumento participativo no encaminhamento das demandas para a construção do Plano Municipal de Economia Solidária, válido para o período de 2018 a 2021.

A lei $n^{\circ} 9.143$ de 30 de novembro de 2017 institui o Plano Municipal de Economia Solidária em virtude das proposições apresentadas na $1^{\text {a }}$ Conferência de Economia Criativa e Solidária de Araraquara. Ao todo, foram tratadas dezenove diretrizes no interior do projeto que versam sobre a postura a ser adotada pelo município. Desse modo, a lei coloca em evidência as estratégias de fomento e dinamização desse segmento da economia, bem como fornece os mecanismos de controle social por parte da sociedade civil e demais agentes sociais. A expansão das iniciativas de promoção da economia alternativa coloca o município de Araraquara no centro da discussão realizada atualmente sobre as estratégias de superação do desemprego, via incentivo e formalização dos empreendimentos econômicos.

A segunda diretriz encaminhada pela conferência, e presente na lei $n^{\circ} 9.143$, trata sobre a criação e regulamentação do Conselho Municipal de Economia Criativa Solidária em novembro de 2018. É possível encontrar o propósito do conselho em função do aprimoramento das práticas de gestão desse segmento, com ampliação da participação política da sociedade civil. O município de Araraquara apresenta, nesse sentido, um desenho institucional representado pela múltipla interação dos mais variados agentes sociais em conjunto com o governo municipal. Assim, o destaque na materialização das políticas públicas para as práticas econômicas alternativas apenas serão compreendidas se forem levados em conta o subsistema atuante no processo de formulação (CAPELLA, 2014).

O governo municipal promoveu, entre os dias 14 e 16 de março de 2019, o I Congresso Internacional de Democracia Participativa. O evento apresentou um profundo debate de acordo com a troca de experiências a respeito de temas como participação popular, democracia, bem como o assunto de maior interesse desse trabalho: a Economia Social e Criativa. Como apresentado pela comissão organizadora do evento, o debate seria estabelecido para alcançar diretrizes estratégicas de políticas públicas para esses setores-chave. Além disso, articulado aos espaços de discussões, houve a realização da Feira Regional de Economia Solidária, Criativa e da Agricultura Familiar, que contou com a presença de mais de cinquenta expositores dos mais variados segmentos. Devido a essa natureza de eventos destacados, se fortalece o argumento sobre a importância de evidenciar o contexto sociopolítico no qual a cidade de Araraquara se encontra atualmente.

A pesquisa, portanto, colocou em evidência a necessidade de compreender a importância desse tipo diverso de economia urbana. A inventividade é um traço comum dos agentes econômicos que estão vinculados a essas práticas, sobretudo em função das pressões exercidas pelas demandas de provisão. Para entender esse fenômeno, é importante que se estabeleça uma rede de articulação entre os indivíduos vinculados às práticas econômicas, os próprios agentes públicos do governo municipal, bem como também entre os intermediadores que organizam os espaços de troca. Cabe, nesse momento, demonstrar o aporte teórico-conceitual que dá embasamento à reflexão proposta pelo artigo.

\section{A dimensão política na discussão apresentada}

O campo das políticas públicas impõe a aproximação entre dimensões do Estado e da sociedade civil que influenciam diretamente na organização econômica e social (SOUZA, 2006). O objetivo é demonstrar, posteriormente, como a abordagem geográfica dos circuitos da economia urbana pode contribuir no universo da promoção de políticas públicas voltadas ao combate das deficiências estruturais do mercado de trabalho. O conhecimento empírico levantado visa, em certo sentido, representar um avanço teórico no campo da compreensão das articulações desenvolvidas entre os segmentos da Economia Criativa e Solidária e o domínio das práticas de gestão territorial.

A promulgação da Constituição de 1988 proporcionou um amplo processo de descentralização política no território brasileiro, possibilitando a inserção de novos sujeitos na arena política. A partir disso, é possível reconhecer a importância dos governos municipais como centros do processo decisório de políticas públicas (CÔRTES, 2007). O município de Araraquara responde a essa tendência, pois recebe papel fundamental na gestão dos processos de resolução das problemáticas do desemprego. Nesse sentido, o enfoque ao combate das dificuldades vivenciadas no mundo do trabalho precisa demonstrar esse pressuposto inicial. 
A gestão do município voltada para a Economia Criativa e Solidária representa, em última instância, o reconhecimento das interfaces socioestatais existentes. O conceito de interface socioestatal ajuda na compreensão dos canais de interação que são construídos entre o quadro governamental e os agentes sociais (PIRES e VAZ, 2014). A elaboração de políticas públicas voltadas para esse segmento econômico demonstra a efetivação da plataforma eleitoral do governo araraquarense, visando à transformação social no plano concreto (SOUZA, 2006). O slogan "Cidade Solidária e Participativa" ganha atenção por reforçar a participação popular enquanto um dos objetivos centrais do governo.

A institucionalização dos espaços públicos participativos é fator fundamental para o envolvimento da sociedade civil nas atividades decisórias de politicas públicas (CÔRTES, 2007). É preciso considerar também a postura das autoridades municipais no que diz respeito à interação da sociedade civil e demais agentes nesse processo. O governo araraquarense aponta para uma cultura política no município relacionada à participação. Nesse sentido, a elaboração de todo o desenho institucional voltado para a aproximação da sociedade civil nos assuntos relacionados às deficiências presente no mundo do trabalho representa uma iniciativa de fomento à participação popular (CÔRTES, 2007). A interação desenvolvida no Conselho Municipal de Economia Criativa Solidária torna-se central, pois constata a ampliação dos sujeitos presentes na articulação do debate e, por conseguinte, no processo de decisão sobre as políticas do setor (CÔRTES, 2007). Em vista do apresentado, Araraquara encontra-se em um contexto de fortalecimento das interfaces socioestatais de participação, fomentando uma cultura política capaz de superar as oscilações conjunturais de troca da gestão municipal.

A partir disso, o município elabora estratégias de combate ao desemprego estrutural contemporâneo, presente no plano nacional e local. A baixa incorporação dos trabalhadores no mercado de trabalho convencional abre espaço para novas estratégias políticas no planejamento municipal. O governo utiliza a Economia Solidária como um importante instrumento do setor de políticas públicas, reconhecendo uma valorização nesse segmento assim como a observada nos anos anteriores a 2016 no país (COSTA, 2016). A busca pela superação das dificuldades vivenciadas no mundo do trabalho viabiliza o contexto geral de fomento dessas práticas no município de Araraquara.

A análise do contexto da Economia Criativa e Solidária evidencia o enfoque na articulação entre a sociedade civil e o quadro governamental do município para essas práticas econômicas. O planejamento municipal incorpora as demandas vindas dos mais variados sujeitos vinculados ao processo, fortalecendo, assim, o subsistema de políticas públicas (CAPELLA, 2014). Cabe demonstrar, a seguir, a teoria dos circuitos da economia urbana, pois ela fornece o aporte teórico capaz de proporcionar avanços no planejamento e compreensão do contexto urbano em Araraquara.

\section{O debate da economia urbana à luz da Geografia}

O Brasil apresenta, em fevereiro de 2019, uma taxa de 12,4\% de desempregados, proporção que atinge, segundo dados do IBGE, um total superior a 13 milhões de brasileiros desvinculados do circuito convencional de produção de valores. Essa constatação delimita a complexidade do mercado atual de geração de riquezas no país, ao passo que, mesmo sem ocupação permanente, os sujeitos estão a todo o momento produzindo, distribuindo e consumindo bens. Dessa forma, a necessidade de se destacar a natureza diversa do mercado de trabalho nacional toma proporções fundamentais na compreensão da problemática.

Levando em conta a especificidade da história dos países subdesenvolvidos, Santos (2018) estabeleceu um novo paradigma de análise da realidade espacial, baseado na teoria dos circuitos da economia urbana. A proposta dessa nova abordagem resulta das deficiências encontradas nas estatísticas nacionais que trataram da temática urbana, mediante modelos transpostos da realidade dos países desenvolvidos, e que contribuíram pouco para o esforço de compreensão do espaço subdesenvolvido em sua totalidade (SANTOS, 2018). O modelo teórico dos circuitos da economia urbana visa, portanto, promover o entendimento do caráter diverso do mercado de produção de valores nacional.

De início, a proposta adotada é superar a visão clássica da economia que segmenta as práticas econômicas. Não compactuamos com a adoção de setor primário, secundário e terciário como forma de compreender a realidade múltipla e complexa do mercado de produção de valores no Brasil. O aporte teórico incorporado na discussão reconhece os circuitos superior e inferior da economia urbana como os instrumentos ideais de interpretação do espaço econômico brasileiro (SANTOS, 2018). Ao considerar esse pressuposto, evidencia-se a fluidez de práticas econômicas que transitam pelos setores e interagem entre si, ao mesmo tempo em que reconhece a diversidade dessas práticas que coexistem na realidade concreta (COSTA, 2016). 
A partir disso, é importante apresentar o contexto de surgimento destes circuitos e caracterizá-los. Em síntese, os dois circuitos da economia urbana levam em conta o conjunto de atividades que são realizadas em distintos níveis de capital, tecnologia e de organização (SILVEIRA, 2015). Sua realidade está estritamente vinculada aos períodos de modernização do território nacional, ou seja, os circuitos são produtos (in)diretos desse novo contexto. O circuito superior caracteriza-se enquanto produto direto da modernização, que leva em conta as atividades organizadas por um alto nível de incorporação de capital. O circuito inferior, por sua vez, surge mediante a necessidade de adaptação do sistema econômico para suprir as necessidades daqueles que não podem recorrer aos consumos e serviços modernos. Ao mesmo tempo, este circuito não moderno funciona como uma estratégia de ocupação laboral não convencional, tendo em vista a capacidade limitada de emprego formal atualmente (SANTOS, 2018).

O enfoque é trabalhar com as práticas econômicas não convencionais, ou seja, atividades que fogem à relação tradicional de assalariamento do trabalho pelo capital. Nesse sentido, é colocado o circuito inferior da economia urbana enquanto representativo dessa realidade, na qual os sujeitos, almejando ocupação laboral, procuram estratégias econômicas de inserção nos ciclos de produção e distribuição de riquezas. O contexto atual, marcado pela flexibilização e aumento do desemprego, promove a multiplicação de iniciativas econômicas atreladas ao conteúdo local de inserção e à baixa utilização de capitais (MONTENEGRO, 2013). Observa-se, portanto, a ampliação do próprio circuito inferior da economia urbana, pois sua marca fundamental é a inventividade dos agentes que recrutam baixos volumes de capitais, aplicando um trabalho intensivo nas atividades econômicas (SANTOS, 2018).

Por essa razão destacada, é fundamental a retomada do circuito inferior da economia urbana enquanto instrumento de compreensão da realidade atual da produção, distribuição e do consumo nas cidades. Essa abordagem deve ser colocada como a dimensão privilegiada de análise contemporânea das realidades urbanas, pois permite levar em conta a especificidade do mercado de trabalho no Brasil atual. A heterogeneidade, desse modo, é a principal característica encontrada e deve ampliar a percepção para além de uma lógica de práticas capitalistas e não capitalistas, alcançando a coexistência como divisor comum. As práticas econômicas atuais, observadas como alternativas ou não convencionais, precisam considerar o potencial de empregabilidade, de sociabilidade desenvolvida, bem como de abrir espaço para uma nova perspectiva de olhar da economia (COSTA, 2016).

Em vista disso, é importante discutir como as atividades econômicas desenvolvidas nas edições da "Rolêfeira" representam a manifestação socioespacial do circuito inferior da economia urbana. Os sujeitos responsáveis pelos empreendimentos econômicos estariam vinculados às práticas alternativas que visam fornecer a provisão familiar dos indivíduos. O contexto atual permite falar em diversas formas de configuração do circuito inferior que se vinculam à adaptação conjuntural e incorporação de novos mecanismos de organização das atividades (SILVEIRA, 2015). Portanto, o caso de uma feira ao ar livre, territorializada no espaço público da Praça do Faveral, faz com que seja possível reconhecer essa forma de manifestação do circuito inferior da economia urbana na cidade de Araraquara.

\subsection{O circuito inferior da economia urbana em Araraquara}

No município araraquarense é possível constatar a existência de espaços de trocas que são locais voltados, acima de tudo, para dar vazão ao empreendimento local. Com o apoio das esferas municipais, se realizam por meio de um trabalho coletivo as edições da "Rolêfeira" na Praça do Faveral. Os eventos ocorrem desde 2017 como uma forma de incentivo e valorização da produção artesanal dos expositores. Nesse sentido, o evento se coloca enquanto uma feira que é, acima de tudo, empreendedora, independente e autônoma em Araraquara. Seu objetivo principal, de acordo com as organizadoras, está centrado em promover a Economia Criativa, Colaborativa e Sustentável, ao passo que constrói um canal de visibilidade entre o produtor local e o público consumidor. Por conseguinte, fortalece a rede de comércio consciente e ecológico, ao mesmo tempo em que lançam mão da (re)ocupação do espaço público com propostas de atividades culturais e artísticas no decorrer das edições das feiras.

Os expositores, ao que tudo indica, vinculam-se a essas práticas para obter a inserção num circuito de produção da provisão familiar se comparada àquelas "empresas solidárias" de feições capitalistas destacadas por Singer (2002). A Economia Criativa araraquarense, nesses moldes, ocorre de forma semelhante àquilo que pode se caracterizar como representativa do circuito inferior da economia urbana. A praça dá o substrato físico de (re)ocupação e (res)significação dos lugares junto das trocas econômicas, permitindo o forte diálogo com economia local de Araraquara. Observa-se que a abrangência desses empreendimentos está intimamente relacionada a uma pequena escala de produção, adaptável de acordo com as necessidades momentâneas de 
provisão. Assim, a aproximação do quadro paradigmático do circuito inferior sustenta-se, pois a tecnologia, nestes empreendimentos, é o trabalho intensivo recriado e adaptado localmente (SANTOS, 2018).

O problema apresentado desenvolve-se em função de compreender o contexto complexo dos circuitos gerais de produção, distribuição e, por conseguinte, de consumo de riquezas. É necessário reconhecer que a problemática apresentada atua como produtora de formas alternativas de geração de renda e provisão familiar. O quadro governamental araraquarense reconhece a importância do fomento às práticas econômicas não convencionais como forma de superação do massivo desemprego contemporâneo. Em certo sentido, o governo municipal dá enfoque às atividades e iniciativas econômicas caracterizadas pela pesquisa enquanto circuito inferior da economia urbana.

Santos (2018) advertiu para o fato dos estudiosos concentrarem esforços somente no entendimento do setor moderno da economia em detrimento da compreensão das práticas surgidas pela ação indireta das modernizações. Também reconheceu o Estado enquanto grande patrocinador dos monopólios, expressão máxima do circuito superior da economia, ao mesmo tempo em que criminalizava e perseguia as atividades econômicas, sobretudo, informais. O município de Araraquara se coloca contrário a essa tendência, pois apresenta um quadro administrativo que fomenta e organiza a expansão dessas iniciativas econômicas não convencionais, buscando superar os estigmas em direção a uma outra prática econômica. Portanto, há um esforço municipal de planificação da Economia Solidária e Criativa, permitindo o avanço na produtividade econômica e espacial da cidade.

A busca pela superação das problemáticas advindas do mundo do trabalho permite deslocar o foco para proposição de um sistema pautado, sobretudo, na concepção do trabalho em correspondência aos princípios econômicos (COSTA, 2016). O mercado de trabalho brasileiro não deve ser observado pela ótica das relações capitalistas tradicionais, pois apresenta uma complexidade que se vincula ao seu próprio processo histórico de formação. A constatação de estratégias econômicas alternativas nas cidades insere-se nessa característica maleável do mercado urbano, principalmente em virtude de sua deterioração que acarreta numa elevada parcela de pessoas sem atividades e rendas permanentes (SANTOS, 2018). Por essa razão, caracterizar um circuito inferior da economia urbana em Araraquara, materializado nas práticas econômicas da "Rolêfeira", demonstra a divisão territorial do trabalho que reconhece a diversidade nos graus de capitalização dos sujeitos (SILVEIRA, 2015). A economia urbana deve ser interpretada, então, por meio desse viés múltiplo das práticas.

\subsection{Caracterização das práticas econômicas alternativas}

A caracterização da manifestação socioespacial do circuito inferior da economia urbana em Araraquara levou em conta o levantamento total de quarenta e quatro (44) empreendimentos que expõem nas feiras de Economia Criativa da "Rolêfeira". Ao longo das respostas obtidas, foi possível reconhecer a presença de empreendimentos econômicos de nove cidades distintas do estado de São Paulo. A destacar: Araraquara $(65,9 \%)$, São Carlos (15,9\%), Ribeirão Bonito (4,54\%), Ibaté (2,27\%), Américo Brasiliense (2,27\%), Guariba (2,27\%), Rio Claro (2,27\%), Matão (2,27\%) e, até mesmo, São Paulo (2,27\%). Dessa maneira, é possível interpretar as edições da feira como um mecanismo de articulação regional da economia urbana, pois une empreendimentos e consumidores em uma escala que ultrapassa a local.

Os empreendimentos econômicos são compostos principalmente por apenas um indivíduo $(61,4 \%)$, ao passo que os empreendimentos que contém dois responsáveis contabilizam $34,1 \%$ e, por fim, os que possuem três ou mais sujeitos compreendem apenas 4,5\% do total de respostas obtidas. A partir disso, é possível reconhecer que, nessas práticas econômicas, o responsável seria o sujeito que assume sozinho a totalidade das funções referentes à sua atividade no circuito inferior (SANTOS, 2018). As iniciativas econômicas que se manifestam espacialmente nas edições da "Rolêfeira" são, nesse sentido, majoritariamente desenvolvidas por uma associação simples de até dois indivíduos.

Os vínculos existentes entre os responsáveis são, sobretudo, os de matrimônio e de parentesco, ambos com 33,3\% dos casos levantados. Em seguida, encontram-se as relações de namoro e amizade, com 19\% e $14,4 \%$, respectivamente. A característica mais marcante, no que diz respeito à associação dos sujeitos, está relacionada com a relação próxima entre os responsáveis pelo empreendimento. Não é possível constatar o nexo tradicional de assalariamento por parte dos agentes econômicos e, por conseguinte, relações de comando do trabalho pelo capital. Essa estratégia permite que nas atividades do circuito inferior a produtividade aumente sem que haja mobilização de mais capital de giro (SANTOS, 2018), ao mesmo tempo em que demonstra uma outra possibilidade de associação dos sujeitos. Portanto, a heterogeneidade encontrada nas relações de trabalho no Brasil representa a permanência das redes de solidariedade familiar que não foram e nem poderiam ser suplantadas pela conveniência da relação salarial (COSTA, 2016). 
A presença do registro de Microempreendedor Individual (MEI) foi identificada em 40,9\% das respostas obtidas. No entanto, a maioria dos empreendimentos atua sem a presença de CNPJ, representando $59,1 \%$ dos negócios pesquisados. Mesmo com o predomínio da informalidade, é fundamental demonstrar a expressividade dos dados referentes à presença do registro MEI. A incerteza no mercado de trabalho convencional incentiva os sujeitos na busca pela montagem e adequação de um pequeno negócio. Nesse sentido, cada vez mais, há a procura pelo enquadramento na categoria como forma de adquirir direitos e maiores benefícios na busca pela provisão familiar. O município também responde a essa tendência, pois se ampliam cada vez mais as iniciativas econômicas que recorrem à formalização. Segundo dados do SEBRAE, no ano de 2019, o município reconheceu um aumento de $23 \%$ na procura e efetivação do MEI, contabilizando o número total de 12.223 registros na cidade.

Desse modo, foi elaborado um banco de dados com todos os empreendimentos econômicos, caracterizando os negócios segundo os produtos que são oferecidos pelos expositores. A Tabela 1 apresenta a proporção das iniciativas econômicas presentes nas edições das feiras de Economia Criativa do coletivo "Rolêfeira" no município de Araraquara. Os empreendimentos foram dispostos de acordo com os segmentos de "artesanato", "alimentação", "roupas", "saúde \& cosméticos", "bebidas" e "outros".

Tabela 1: Relação dos segmentos de mercadorias.

\begin{tabular}{ccc}
\hline Segmento & Número & Porcentagem \\
\hline Artesanato & 17 & $38,6 \%$ \\
Alimentação & 13 & $29,5 \%$ \\
Roupas & 8 & $18,2 \%$ \\
Saúde \& Cosméticos & 4 & $9,1 \%$ \\
Bebidas & 1 & $2,3 \%$ \\
Outros & 1 & $2,3 \%$ \\
Total & 44 & $100 \%$ \\
\hline
\end{tabular}

Fonte: Elaborada pelo autor

A maior parte dos empreendimentos vende somente para o consumidor final $(77,3 \%)$, ao passo que $22,7 \%$ transfere suas mercadorias para intermediários econômicos. Essa forma de funcionamento dos empreendimentos reforça ainda mais a importância dos canais de comunicação entre os agentes econômicos e os potenciais consumidores. Em razão disso, o enfoque dado aos consumidores finais é o objetivo central dos sujeitos que se vinculam às práticas econômicas alternativas na cidade de Araraquara.

No que diz respeito ao local de comércio das mercadorias, os agentes ressaltaram a importância das feiras de Economia Criativa, já que, para a totalidade dos empreendimentos, esse é o mais expressivo canal de realização de suas vendas. Ao mesmo tempo em que 59,1\% destacou que operam suas trocas em seus domić́lios. Em 13,6\% dos casos, os sujeitos comercializam seus produtos nas ruas, ao passo que apenas 2,3\% salientou a presença de uma loja física do empreendimento. Em razão dessas características encontradas, é possível demonstrar como as feiras são uma importante ferramenta de efetivação de suas mercadorias. A pequena escala das atividades é outro aspecto possível de se relatar, pois, devido à pequena dimensão de suas práticas, elas acabam sendo alojadas nas casas dos agentes (SANTOS, 2018). Podemos destacar essa estratégia como uma racionalidade que visa diminuir os custos de sua produção, na medida em que a maioria dos empreendimentos não possui segurança financeira para arcar com aluguéis comerciais.

A propaganda dos empreendimentos é praticada mediante dois principais instrumentos, sendo eles as redes sociais $(100 \%)$ e a eventual propaganda pelo boca a boca $(86,4 \%)$. Apenas $2,3 \%$ dos empreendimentos recorrem às mídias tradicionais de rádio e televisão. Nos finais da década de 1970, Santos (2018) demonstrou a baixa utilidade da publicidade no circuito inferior da economia urbana, bem como a sua própria inviabilidade devido ao custo representado. A proximidade com a clientela proporcionava a superação do obstáculo da falta de propaganda existente nas atividades econômicas. Porém, atualmente, vale ressaltar o aumento progressivo da publicidade nas práticas do setor inferior, sobretudo pela incorporação das redes sociais como instrumento de divulgação dos trabalhos. A publicidade pelo Facebook e Instagram alia-se aos tradicionais cartões de visita, faixas e boca a boca (MONTENEGRO, 2013), pois representam um custo mínimo ou inexistente no orçamento dos sujeitos.

No que diz respeito à organização do empreendimento, quase a totalidade $(86,4 \%)$ pontuou que faz encomenda de seus produtos, restando uma parcela mínima $(13,6 \%)$ agindo a pronta-entrega. A grande presença de empreendimentos procedendo também por meio de encomendas demonstra como os agentes econômicos precisam expandir suas práticas econômicas. Em vista disso, inserem-se numa possibilidade 
econômica que vai para além dos dias em que ocorrem as edições das feiras de Economia Criativa do coletivo "Rolêfeira".

As formas de pagamento são preferencialmente realizadas por meio de transações em dinheiro líquido, operação que prevalece como tradicional nas atividades do circuito inferior (SANTOS, 2018). Porém, é possível destacar as transformações ocorridas pela incorporação dos recursos de transações financeiras nos empreendimentos, ou seja, adesão aos cartões de débito $(88,6 \%)$ e de crédito $(86,4 \%)$. As finanças representam, ao lado do consumo, da tecnologia e da informação, uma das variáveis centrais do período atual que moldam as relações sociais desenvolvidas nesse circuito (MONTENEGRO, 2013). Pode-se destacar que, dentre os empreendimentos que utilizam esses instrumentos, a empresa PagSeguro obteve maior presença, alcançando 60,9\% dos agentes. Em segundo lugar, com 9,75\%, aparecem as empresas Mercado Pago, SumUp e GetNet. Por fim, as empresas Cielo e Stelo foram presentes em apenas 4,87\% dos empreendimentos. A banalização do acesso ao mundo financeiro representa um novo constituinte do período atual que rebate na organização desses empreendimentos, sobretudo em razão das facilidades de inserção nessas novas prestadoras de serviços de crédito.

Em $72,7 \%$ dos empreendimentos os agentes mantém a contabilidade dos negócios, enquanto que no restante $(27,3 \%)$ não há nenhum tipo de registro do caixa. Sobre a renda mensal aproximada dos empreendimentos, $36,4 \%$ dos sujeitos indicaram que seus negócios movimentam até $\mathrm{R} \$ 500,00$, ao passo que $34,1 \%$ destacou que arrecada um valor no intervalo de $\mathrm{R} \$ 500,00$ até $\mathrm{R} \$ 1.000,00$. Nos valores de $\mathrm{R} \$$ $1.000,00$ a $\mathrm{R} \$ 1.500,00$ e acima de $\mathrm{R} \$ 1.500,00$, foi constatado $13,6 \%$ e $15,9 \%$, respectivamente. Dessa forma, as informações destacadas apontam na direção da deficiência estrutural dos empreendimentos no que diz respeito ao volume de negócios movimentados mensalmente. No circuito inferior da economia urbana, as práticas econômicas tendem a possuir uma baixa movimentação global dos negócios, representando uma pequena escala econômica (SANTOS, 2018). Entretanto, é fundamental ressaltar que a racionalidade por detrás dessas iniciativas está vinculada a uma estratégia de inserção nos circuitos gerais de produção de valores, com enfoque na organização da provisão familiar.

A divisão da renda nos empreendimentos com mais de um responsável é feita de modo igualitário em $71,4 \%$ dos casos, sendo elaborada de forma diferencial em $28,6 \%$. A prática de divisão igualitária abre espaço para a constatação de novas metodologias de gestão dos empreendimentos. Os agentes econômicos demonstram uma mudança de paradigma na associação entre as pessoas, pois levam em conta os processos de cooperação solidária e a inserção do público que não se encaixa nos modelos de emprego convencionais (COSTA, 2016). A partir disso, a constituição do circuito inferior da economia urbana também leva em conta os elementos de uma prática econômica solidária em comparação à capitalista (SINGER, 2002).

No que diz respeito à inserção dos sujeitos no mercado de trabalho convencional, pouco mais da metade $(52,3 \%)$ respondeu que o empreendimento é, no momento, a única fonte de renda, ao mesmo tempo em que $47,7 \%$ destacou emprego no mercado tradicional. É possível, em certa medida, relacionar essa constatação como representante da tendência do circuito inferior em caracterizar relações que não são as de assalariamento entre os sujeitos. Os empreendimentos como principal fonte de renda dos sujeitos demonstram a importância dessas práticas enquanto estratégia alternativa para aqueles que não conseguem absorção pelo mercado de trabalho, bem como uma captação extra de recursos para compor a renda familiar. Portanto, é fundamental ter em vista essa dupla relação presente na manifestação socioespacial do circuito inferior da economia urbana em Araraquara.

\subsection{A retomada do espaço público na Praça do Faveral}

A iniciativa de feiras criativas no município de Araraquara em função das edições da "Rolêfeira" abre espaço para o debate da ressignificação dos espaços públicos na cidade. A abordagem da produção do espaço público reconhece, em certa medida, a própria questão da produção geral do espaço. O entendimento desse fenômeno perpassa fundamentalmente pelo conteúdo transversal de três perspectivas analíticas distintas. É preciso considerar o nível da dominação política, da acumulação capitalista, bem como da realização da vida humana (CARLOS, 2014). O enfoque central, apesar de vislumbrar as três concepções, está relacionado, sobretudo, com os processos e dinâmicas presentes na dimensão de realização da vida humana no contexto da sociabilidade araraquarense.

A existência das edições da "Rolêfeira" demonstra como os conteúdos da produção do espaço urbano levam em conta a ação concreta dos sujeitos sociais, que são dotados de intencionalidades, projetos e interesses próprios (CORRÊA, 2014). Esses eventos são observados pela ótica da apropriação do espaço público, pois aqui a centralidade se vincula às práticas socioespaciais produzidas pelo uso que desenvolvem o plano do vivido e resultam na relação de pertencimento com o espaço público (SOBARZO, 2006). O uso e 
ocupação da Praça do Faveral acontecem de acordo com o conjunto de amigos, familiares, casais, segmentos populacionais das mais variadas faixas etárias que frequentam as edições como uma possibilidade de materializar práticas cotidianas de lazer, consumo e circulação (SOBARZO, 2006), ao passo em que também ocorrem as exposições dos empreendimentos alternativos da economia. Em vista disso, é possível fortalecer o argumento dessas iniciativas como forma de articular a dimensão econômica, cultural e simbólica nos espaços públicos esquecidos pelo contexto de fortalecimento dos locais privados de lazer (CARLOS, 2014).

$\mathrm{O}$ quadro apresentado pelo município de Araraquara permite caracterizar o governo enquanto um agente importante no processo de institucionalização dessa revalorização dos locais públicos. Demonstra-se a presença da prefeitura desempenhando múltiplos papéis no interior desse fenômeno, principalmente em relação à promoção da legalidade dos eventos. O Estado, em última instância, é a arena de ajustamento dos diversos interesses presentes em qualquer contexto socioespacial (CORRÊA, 2014). No entanto, as iniciativas da "Rolêfeira" devem ser reconhecidas como o produto da associação de sujeitos engajados num projeto de transformação social da realidade. O contexto de opressão no mundo do trabalho e da pauperização humana em geral fortalecem o surgimento de reinvindicações por mudanças com distintas formas populares de organização, transformando a experiência no impulso pela construção de novos cenários de vida na atualidade (GAIGER, 2009). Em Araraquara, existe uma convergência de interesses no que diz respeito à consolidação desse quadro geral de fomento às iniciativas de ressignificação dos espaços públicos, sobretudo pela forte articulação de segmentos da sociedade civil com o governo municipal. A "Rolêfeira" é produto desse esforço coletivo entre sujeitos sociais de vários segmentos, que fortalecem uma rede de cooperação com a prefeitura ao incentivar uma agenda cultural duradoura na cidade.

O fenômeno das feiras de Economia Criativa demonstra uma alternativa na política pública municipal para a superação de duas grandes deficiências presentes no contexto atual. Primeiramente, visam o combate às dificuldades vivenciadas na geração de renda pelos sujeitos em razão do momento problemático de desemprego atual. $\mathrm{O}$ circuito inferior da economia urbana cumpre, dessa maneira, papel fundamental nesse fenômeno de inserção dos sujeitos nos ciclos produtivos alternativos. Por fim, articulam a construção de um cronograma de eventos apresentado como a oferta de uma programação cultural e artística sem restrições de acesso.

O movimento de apropriação do espaço público promove o vínculo dos pressupostos relacionados à ideia de lugar. A construção do lugar demonstra a dimensão da afetividade presente na relação socioespacial das práticas dos sujeitos com o ambiente construído, reconhecendo que suas demandas se estendem para além das necessidades materiais (CARLOS, 2014). Em vista disso, a prática socioespacial dos sujeitos que frequentam a "Rolêfeira" amplia a experiência do vivido na cidade em direção ao envolvimento de aspectos simbólicos do imaginário coletivo, pois fomentam um potencial transformador da realidade ao promover a sociabilidade entre os indivíduos no espaço urbano (SOBARZO, 2006). A consolidação das edições das feiras econômicas, por conseguinte, vislumbra uma alternativa criativa à lógica dominante de produção do espaço, reforçando a retomada do espaço público pelos agentes sociais não hegemônicos (SOBARZO, 2006). Os eventos devem ser observados pelo viés do pertencimento ao espaço, pois revalorizam a sociabilidade pautada na convivência no espaço público, na medida em que promovem encontros entre diversas pessoas. Portanto, a planificação incorpora na agenda governamental a Praça do Faveral enquanto o substrato físico para que esse conjunto de relações socioeconômicas, culturais e simbólicas se desenvolva no tecido urbano de Araraquara.

\subsection{A nova feição do circuito inferior da economia urbana}

A permanente transformação da realidade social demanda uma constante revisão dos conteúdos conceituais responsáveis por compreender determinado fenômeno em questão (LENCIONE, 2008). O circuito inferior da economia urbana representa, assim, uma realidade em constante renovação ao longo do processo histórico. É importante ressaltar como as mudanças conjunturais produzem novas exigências para o setor inferior da economia em direção a uma nova manifestação socioespacial. As demandas do contexto contemporâneo estão relacionadas, sobretudo, com a superação das problemáticas presentes no mundo do trabalho e, nesse sentido, surgem novas estratégias econômicas dos sujeitos para a garantia da provisão. Os circuitos encontram novas feições em função do contexto socioespacial do município de Araraquara, marcado pelo surgimento das feiras de Economia Criativa e da gestão pública favorável.

O estabelecimento das interações entre os diversos agentes sociais com a organização municipal permite reconhecer o circuito inferior enquanto um fenômeno que busca os elementos de sua articulação na escala local. A manifestação socioespacial do circuito inferior da economia urbana em Araraquara é a convergência de vetores sociais capazes de promover as edições das feiras criativas como representativas desse circuito. A organização do evento demonstra o alto poder de transformação da sociedade civil quando bem alinhada em função de um interesse concreto. Em síntese, o exemplo da "Rolêfeira" reforça o fenômeno das feiras ao ar 
livre que revalorizam e articulam a dimensão econômica nos espaços públicos em esquecimento, no momento em que o foco é trazer visibilidade aos empreendimentos alternativos. Essas iniciativas retomam o espaço das praças e caracterizam-se como importantes, pois vão à contramão do momento atual em que a sociabilidade dos espaços públicos do encontro se resume a ambientes fechados (CARLOS, 2014).

A dimensão cultural, nesse sentido, é evidenciada no decorrer dos eventos da "Rolêfeira". A cada edição apresenta-se uma temática principal na qual o figurino, as intervenções culturais e os artistas selecionados correspondem à proposta. Existe uma estética cultural que busca inserir os participantes no contexto sugerido, trazendo a presença cada vez maior de pessoas enquanto potenciais consumidores. Ao mesmo tempo, a revitalização do espaço público acontece de modo material e imaterial, pois restaura o espaço construído, bem como requalifica a função de interesse social das praças. $\mathrm{O}$ evento torna evidente a proposta de articular a dimensão econômica com as dimensões culturais e simbólicas de retomada do espaço público, que reforçam, em certo sentido, o associativismo dos sujeitos, a solidariedade e a democracia no espaço urbano.

Sobre os empreendimentos, encontra-se uma verdadeira adesão de novos mecanismos e instrumentos que correspondem às mudanças técnicas do contexto atual. $\mathrm{O}$ desenvolvimento tecnológico caminha de forma a tornar alguns de seus elementos banais e, por conseguinte, passíveis de serem incorporados pelo circuito inferior. Novos recursos como os de vendas on-line, máquinas de cartão de crédito e débito, bem como a realização de propaganda mediante o uso das mídias de informação digital reforçam essa nova feição do circuito inferior da economia urbana que, cada vez mais, incorpora elementos da modernidade (SILVEIRA, 2015). Os agentes do setor inferior realizam suas trocas por meio dessas ferramentas, ao mesmo tempo em que mantém comportamentos representativos do circuito inferior clássico, ou seja, reaproveitamento de matérias primas, reciclagem de produtos e a reutilização de recursos para redução de custos (SANTOS, 2018). Portanto, podemos demonstrar como as transformações sociais permitem novas incorporações de elementos no circuito inferior, ao passo que persistem práticas tradicionais.

O desenvolvimento da pesquisa reconheceu a apropriação do registro de Microempreendedor Individual (MEI) como um fenômeno a ser considerado. Em certa medida, é possível retratar a incorporação do MEI enquanto o novo mecanismo de expansão e adequação na formalidade dos empreendimentos do circuito inferior da economia urbana. Tradicionalmente, as atividades econômicas desse circuito eram confundidas com os setores informais, reconhecendo os dois fenômenos como correspondentes. A manifestação socioespacial do circuito inferior da economia urbana em Araraquara incorpora o MEI como instrumento de uma rede maior de segurança no mundo do trabalho, sobretudo na medida em que esse circuito revela instabilidade para os seus agentes econômicos.

O circuito inferior da economia urbana representa um fenômeno híbrido na realidade socioespacial, pois incorpora elementos da modernidade ao mesmo tempo em que mantém práticas tradicionais. As estratégias de provisão dos agentes caminham em correspondência com as transformações conjunturais, mantendo sempre o objetivo final de reprodução social do cotidiano familiar. Desse modo, o paradoxo do circuito inferior é evidenciado pelo trânsito entre as variáveis modernas que controlam o período atual (MONTENEGRO, 2013) e a racionalidade tradicional desse setor, representada pelas técnicas não modernas de produção e organização dos empreendimentos (SANTOS, 2018).

\section{Considerações finais}

A reflexão apresentada procurou articular um complexo de procedimentos metodológicos relacionados aos trabalhos de campo, aplicação de questionários, realização de entrevistas e à reflexão teórica, servindo como síntese sobre o objeto de estudo (LAKATOS e MARCONI, 1983). A partir disso, foi possível o aprofundamento na temática da Economia Criativa e Solidária em Araraquara, adotando uma abordagem geográfica que permitiu analisar a manifestação socioespacial do circuito inferior no município, bem como ressaltar a "Rolêfeira" como uma iniciativa de apropriação do espaço público pensada pela sociedade civil.

O intuito da discussão realizada foi destacar como o debate sobre a Economia Criativa e Solidária se assemelha aos pressupostos presentes na teoria dos circuitos da economia urbana. A existência das feiras econômicas, representadas pelas edições da "Rolêfeira", assegura as iniciativas que se voltam à produção da provisão familiar dos agentes, ao mesmo tempo em que fortalece os conteúdos da sociabilidade mediante o aprofundamento das relações de pertencimento com o espaço construído. Dessa forma, o processo de pesquisa permite reconhecer a Economia Criativa e Solidária em Araraquara como a ressignificação do circuito inferior da economia urbana. Qualificar as atividades que ocorrem nas feiras criativas de Araraquara como quadro referencial do circuito inferior parece correto, pois são constituídas, sobretudo, por formas de produção com baixo capital tecnológico, bem como pelo pequeno comércio não moderno (SANTOS, 2018). 
O quadro analisado nesse fenômeno toma proporções ainda mais dramáticas pelo fato de países que alcançaram tardiamente o cenário industrial revelarem um profundo processo de mudança na estrutura socioeconômica e espacial de modo concentrado (SINGER, 1998). Mais da metade dos sujeitos responsáveis pelos empreendimentos apontaram essas iniciativas como sua única fonte de rendimento. O contexto atual de precarização do trabalho e de incapacidade de absorção nos circuitos formais de emprego (GAIGER, 2015) permite reconhecer o caráter fundamental das iniciativas alternativas produzidas pelos sujeitos econômicos. Assim, o surgimento dessas iniciativas toma a feição de uma estratégia de inserção na produção e distribuição de riquezas, via circuito inferior da economia urbana. A abordagem da pesquisa compreende o circuito inferior como um mecanismo alternativo de integração permanente desses sujeitos "ao meio construído, ao trabalho e ao mercado", pois as "diferenças de renda e o tamanho das cidades permitem a coexistência de formas diversas de produção e consumo" (SILVEIRA, 2015, p.255). A própria acumulação no circuito inferior deve ser observada, então, pelo viés oposto do setor superior da economia urbana, tendo como enfoque a reprodução familiar do cotidiano e a importância da inserção esporádica nos circuitos modernos de consumo (SANTOS, 2018).

Admitindo a necessidade de retomada do circuito inferior da economia na planificação urbana (SANTOS, 2018), o baixo volume financeiro levantado pelas unidades de produção em suas atividades torna essa característica cada vez mais essencial. As atividades do circuito inferior, via de regra, não dispõem dos incentivos do planejamento governamental em suas práticas. Entretanto, a ressignificação do circuito inferior da economia urbana por meio da Economia Solidária e Criativa em Araraquara se apresenta como uma possibilidade alternativa para a ampliação de sua produtividade espacial e econômica.

O município araraquarense, dessa forma, apresenta um quadro distinto ao articular o fomento dessas práticas em função do desenho institucional existente na cidade. Encontra-se uma outra possibilidade de prática econômica que leva em conta a superação das problemáticas estruturais no mundo do trabalho. A promoção dessas iniciativas econômicas dos sujeitos fortalece a constituição de novos modelos de trabalho e gestão dos empreendimentos, pois permitem padrões de cooperação solidária, inclusão e sustentabilidade econômica (COSTA, 2016). Em síntese, essas atividades de pequena escala devem ser vistas como centrais nas políticas públicas por sua capacidade de incorporar os sujeitos sociais na vida econômica local, sobretudo pelo fortalecimento da planificação municipal em função da Economia Criativa e Solidária de Araraquara.

\section{Agradecimentos}

$\mathrm{O}$ desenvolvimento da pesquisa apresentada por meio deste artigo recebeu o apoio financeiro pelo processo $n^{\circ}$ 2019/24895-3, Fundação de Amparo à Pesquisa do Estado de São Paulo (FAPESP). O financiamento demonstrou-se fundamental para incentivar o engajamento e determinação na produção desse material, pois o retorno social sempre foi visto como o objetivo maior da pesquisa. Por fim, é necessário que se façam os agradecimentos individuais às pessoas que mais contribuíram ao longo desse processo. A destacar, ao professor Rafael Alves Orsi, na condição de orientador e supervisor do projeto, e à minha companheira Raissa Carvalho Ribeiro pela constante revisão técnica e gramatical de todo o material elaborado para a realização desse trabalho científico.

\section{Referências}

CAPELLA, Ana Cláudia Niedhardt; BRASIL, Felipe Gonçalves. Subsistemas, comunidades e redes para a análise da participação no processo de políticas públicas. Revista Brasileira de Politicas Publicas, v. 4, n. 2, p. 65, 2014. DOI: http://dx.doi.org/10.5102/rbpp.v4i2.2912

CARLOS, Ana Fani Alessandri. Da "organização" à "produção" do espaço no movimento do pensamento geográfico. In: CARLOS, Ana Fani Alessandri; SOUZA, Marcelo Lopes de; SPOSITO, Maria Encarnação Beltrão (orgs.). A produção do espaço urbano: agentes e processos, escalas e desafios. São Paulo: Contexto, 2014. p. 53-73

CARLOS, Ana Fani Alessandri. O poder do corpo no espaço público: o urbano como privação e o direito à cidade. GEOUSP Espaço e Tempo (Online), v. 18, n. 3, p. 472-486, 12 dez. 2014. DOI: https://doi.org/10.11606/issn.2179-0892.geousp.2014.89588

CORRÊA, Roberto Lobato. Sobre agentes sociais, escala e produção do espaço: um texto para discussão. In: CARLOS, Ana Fani Alessandri; SOUZA, Marcelo Lopes de; SPOSITO, Maria Encarnação Beltrão (orgs.). 
A produção do espaço urbano: agentes e processos, escalas e desafios. São Paulo: Contexto, 2014. p. 41 51 .

CÔRTES, Soraya Vargas. Viabilizando a participação em conselhos de política pública municipais: arcabouço institucional, organização do movimento popular e policy communities. In: HOCHMAN, Gilberto; ARRETCHE, Marta; MARQUES, Eduardo (orgs.). Políticas Públicas no Brasil. Rio de Janeiro: Fiocruz, 2007. p. 125-145.

COSTA, Sibelle Cornelio Diniz da. Do precário ao plural: realidades e possibilidades da economia popular no Brasil contemporâneo. Tese (Doutorado em Economia) - Faculdade de Ciências Econômicas, Universidade Federal de Minas Gerais (UFMG). Belo Horizonte, p. 204. 2016.

GAIGER, Luiz Inácio. A economia solidária na contramarcha da pobreza. Sociologia, Problemas e Práticas, Lisboa, n. 79, p. 43-63, set. 2015. DOI: http://dx.doi.org/10.7458/SPP2015793556

GAIGER, Luiz Inácio. Antecedentes e expressões atuais da economia solidária. Revista Crítica de Ciências Sociais, Coimbra, n. 84, p. 81-99, mar. 2009. DOI: https://doi.org/10.4000/rccs.401

HESPANHA, Pedro. Da expansão dos mercados à metamorfose das economias populares. Revista Crítica de Ciências Sociais, Coimbra, n. 84, p. 49-63, mar. 2009. DOI: https://doi.org/10.4000/rccs.390

LAKATOS, Eva Maria; MARCONI, Marina de Andrade. Metodologia científica. São Paulo: Atlas, 1983.

LENCIONE, Sandra. Observações sobre o conceito de cidade e urbano. GEOUSP Espaço e Tempo (Online), v. 12, n. 1, p. 109-123, 30 abr. 2008. DOI: https://doi.org/10.11606/issn.21790892.geousp.2008.74098

MONTENEGRO, Marina Regitz. Dinamismos atuais do circuito inferior da economia urbana na cidade de São Paulo: expansão e renovação. GEOUSP Espaço e Tempo (Online), n. 34, p. 33-45, 30 ago. 2013. DOI: https://doi.org/10.11606/issn.2179-0892.geousp.2013.74933

PIRES, Roberto R. C.; VAZ, Alexander C. N.. Para além da participação: interfaces socioestatais no governo federal. Lua Nova, São Paulo, n. 93, p. 61-91, dec. 2014. DOI: https://doi.org/10.1590/S010264452014000300004

SANTOS, Milton. O espaço dividido: os dois circuitos da economia urbana dos países subdesenvolvidos. 2. ed. São Paulo: Edusp, 2018.

SILVEIRA, María Laura. Modernização contemporânea e nova constituição dos circuitos da economia urbana. GEOUSP Espaço e Tempo (Online), v. 19, n. 2, p. 245-261, 3 nov. 2015. DOI: https://doi.org/10.11606/issn.2179-0892.geousp.2015.102778

SINGER, Paul. A economia política da urbanização. 14. ed. São Paulo: Contexto, 1998.

SINGER, Paul. Introdução à economia solidária. São Paulo: Perseu Abramo, 2002.

SOBARZO, Oscar. A produção do espaço público: da dominação à apropriação. GEOUSP Espaço e Tempo (Online), v. 10, $\quad$ n. 2, $\quad$ p. 93-111, 30 dez. 2006. DOI: https://doi.org/10.11606/issn.21790892.geousp.2006.73992

SOUZA, Celina. Políticas públicas: uma revisão da literatura. Sociologias, Porto Alegre, n. 16, p. 20-45, Dec. 2006. DOI: https://doi.org/10.1590/S1517-45222006000200003

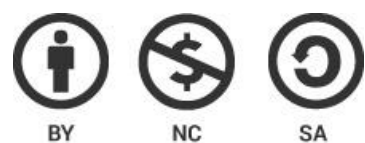

Este artigo é distribuído nos termos e condições do Creative Commons Attributions/AtribuiçãoNãoComercial-CompartilhaIgual (CC BY-NC-SA). 